\title{
Educación Literaria: reconocimiento complejo y participación legítima del lector literario como actos de justicia educativa'
}

\author{
Literary Education: Complex Recognition and Legitimate Participation \\ of the Literary Reader as Acts of Educational Justice
}

\author{
RICARDO SÁNCHEZ LARA \\ SOFÍA DRUKER IBÁNEZ \\ Universidad Católica Silva Henríquez (UCSH) \\ Universidad Academia de Humanismo Cristiano (UAHC) \\ Chile \\ rsanchezl@ucsh.cl \\ sofia.druker@gmail.com
}

(Recibido: I8-O2-2020; aceptado: $02-07-2020$ )

Resumen. El objetivo de este artículo es analizar la lectura literaria escolar, específicamente, el reconocimiento y la participación como categorías epistémicas y políticas que operan en los encuentros lectoliterarios en la escuela, desarrollando dos perspectivas de revisión: la experiencia lectora y la distinción de dos caminos explicativos sobre el conocimiento; uno que lo sitúa como revelación de la realidad, y otro que lo concibe como construcción de mundo en la experiencia. Metodológicamente, este trabajo corresponde a una revisión teórica que busca articular las dimensiones epistémicas, políticas y didácticas de las configuraciones posibles del reconocimiento y la participación imbricadas en distintas concepciones de la educación literaria. Para ello, desde una mirada interpretativa, se realiza una aproximación conceptual a la díada conocimiento/realidad, luego se describen aspectos de la experiencia lectora y, finalmente, se desarrolla un enfoque crítico sobre la lectura literaria en la escuela, situando la reflexión en el campo de la justicia educativa como condición para la justicia social. Entre las principales conclusiones destacan: la necesidad de complejizar el reconocimiento epistémico y político del lector literario escolar para habilitar su participación expresiva y la necesidad de situar la reflexión didáctica de la educación literaria más allá de lo metodológico.

Palabras clave: educación literaria; experiencia lectora;reconocimiento;participación;justicia educativa.

\footnotetext{
${ }^{\text {I }}$ Para citar este artículo: Sánchez Lara, Ricardo y Druker Ibáñez, Sofía (2O2I). Educación Literaria: reconocimiento complejo y participación legítima del lector literario como actos de justicia educativao. Alabe 23 [www.revistaalabe.com]

DOI: IO.I5645 Alabe2O2I.23.8
} 
Abstract. This paper aims to analyze school literary reading, specifically, recognition and participation as epistemic and political categories that operate in school reading and writing encounters, developing two perspectives of revision: the reading experience and the distinction of two explanatory paths about knowledge; one that situates it as a revelation of reality, and the other that conceives it as a construction of the world within experience. Methodologically, this work corresponds to a theoretical review, which seeks to articulate the epistemic, political and didactic dimensions of the possible configurations of recognition and participation interwoven in different conceptions of literary education. To this end, from an interpretative viewpoint, a conceptual approach to the knowledge/reality dyad is made, then aspects of the reading experience are described, and finally, a critical approach to literary reading in school is developed, placing the discussion in the field of educational justice as a condition for social justice.Among the main conclusions, the following stands out: the need to make the epistemic and political recognition of the school literary reader more complex in order to enable their expressive participation and the need to situate the didactic reflection of literary education beyond the purely methodological.

Keywords: literary education, reading experience, recognition; participation; educational justice. 


\section{I.- Un marco introductorio}

No sería fértil definir la lectura sin la aceptación de su constitución múltiple y consensual. En los contornos de sus prácticas, en tanto actividad social, coexisten dimensiones políticas, epistémicas y culturales que, siguiendo a Ramírez Leyva (2OIO), la tornan una actividad inagotable e irreductible.

Podría entonces partir asumiéndose que todas las cosas que se leen se leen en la experiencia contextual de existir con otros en comunidades de práctica y sentido (Gee, 20I5), cuya constitución depende tanto de dinámicas endógenas de producción y reproducción de realidad como del lugar específico, siempre intersticial, que cada comunidad ocupa en redes más amplias de subordinación y hegemonía (Iribarren Donadeu, 20I6). La lectura, de esta forma, se transforma en las lecturas, y sus sentidos y usos en construcciones legitimadas, como señalara Rockwell (2OOI), dadas ciertas condiciones materiales y simbólicas de actualización.

En la escuela, la institucionalización del fenómeno lector ha supuesto la adopción de ciertos modos relacionales y sentidos particulares definidos por discursos de poder. Es decir, sus usos están constreñidos, como toda acción cultural, por las distinciones y delimitaciones que son parte de la práctica hegemónica.

En particular, la validación sistémica de la comprensión de lectura y los repertorios de legitimación que la soportan, han construido un entramado de múltiples disposiciones técnicas que cobran relevancia en el contexto específico de la escuela y que se han naturalizado como fundamentales para la participación ciudadana, descartando otras concepciones lectoras e invisibilizando espacios culturales subalternos.

De este modo, en la literacidad escolar (o en el desarrollo de un tipo particular de relación con lo letrado que es propio de la escuela), la comprensión de lectura no refiere necesariamente a la producción de relaciones significativas con lo que se lee, sino que, más bien, nominaliza un conjunto de procedimientos a los que se atribuye sentido y valor universal, tales como explicaciones descriptivas, recuperación de inferencias, descontextualización del autor (también de las audiencias) y atención selectiva a los elementos de un texto escrito (Zavala, 2009; Heath, I982).

La naturalización de este particular entendimiento sobre la comprensión lectora, unido a las pretensiones de universalidad que de ella emergen, obscurecen su dimensión política y crean condiciones para la tecnificación de los procesos de enseñanza y aprendizaje como prácticas que, estructuralmente, disponen mecanismos de acomodación y homogeneidad (Zavala, 2OOI, 2002, 2OI9; Ferreiro, 2004; Gamboa, et al. 20I6; Ocampo y López-Andrada, 20r9a).

En un contexto marcado por la prevalencia de lógicas educativas de competitividad, reflejadas en el incremento e instalación de sistemas evaluativos estandarizados (Caracas y Ornelas, 2OI9), esta concepción en torno a la lectura se convierte en piedra angular de la literacidad escolar entendida como "un conjunto delimitado de habilidades cognitivas, que sirven de soporte para la actividad de lectura y escritura, la que puede ser medida 
transnacionalmente al margen del contexto sociocultural en el que se sitúan las personas" (Riquelme y Quintero, 20I7:95).

Además de lo dicho en el párrafo anterior, la tecnificación escolar de la lectura instrumentaliza los procesos de aprendizaje presuponiendo neutralidad ideológica (Zavala, 2OI9), reducela complejidad del sujeto (también del procesolector), homogeneiza los significados, subordina la lectura a la medición y separa los usos de los contextos, a través de una enseñanza monomodal y monocultural que, en definitiva, inhabilita la legitimidad participativa. En este escenario, se han instalado premisas asociadas al déficit comprensivo, a la necesidad remedial de mejorar los estándares de desempeño lector y, como señalan Ocampo y López-Andrada (20I9b), al diseño de políticas compensatorias.

La lectura literaria escolar no está ajena a esta disposición técnica. En múltiples revisiones se ha constatado que la enseñanza de la literatura se ha tecnificado para el entrenamiento de habilidades comunicativas-funcionales, para la desubjetivación de las experiencias, para la reproducción de una racionalidad de control y para el desarrollo subsidiario y marginal de la creatividad (Sawaya, 20I6; Cuesta, 20I6; Saavedra Rey, 2OII).

Una postura naturalizada en este panorama de tecnificación es que las dificultades en la comprensión de lectura devienen principalmente de las condiciones socioeconómicas y culturales de los estudiantes. Contrario a ello, sostenemos que el problema de la lectura, particularmente literaria escolar, radica en la dimensión epistémica y política de los reconocimientos que operan en ella, entendiendo reconocimiento como un principio afirmativo de justicia que supone la concepción de la otredad como diferencia e igualdad (Fraser, 2008), es decir, como realidad compleja que se distingue en la multiplicidad constitutiva y que habita, como advierte Honneth (2006), tanto en los discursos ideológicos como en las prácticas sociales.

En efecto, el reconocimiento es una afirmación de las dimensiones sociales, políticas y epistémicas de los sujetos, conforme a marcos normativos y consensos culturales que operan en instituciones y comunidades. La lectura literaria, dada la tecnificación escolar señalada, reconoce en el lector (tras disposiciones que devienen del entramado curricular, político y epistémico) a un sujeto competencial que asigna significados en ciertas condiciones y con ciertas destrezas aprendidas en la experiencia escolar; experiencia en la que, en términos generales, la comprensión de lectura subsiste como tecnología monomodal y monocultural que homogeniza los sentidos e invisibiliza las dimensiones diferenciadoras.

Este reconocimiento técnico del lector literario escolar, (también del profesorado y de los textos), determina, epistémica y políticamente, los modos de participación lectora y las condiciones de su didactización. De este modo, los reconocimientos parciales, devenidos de la mirada técnica prevalente en el escenario escolar, se traducen en participaciones ilegítimas y actualizaciones de injusticias que se reproducen (naturalizadas) en la didactización de la literatura escolar.

Desde un enfoque crítico en torno a las relaciones de hegemonía y conocimiento que constituyen el actual espacio de la educación literaria, el objetivo de este trabajo es 
analizar la lectura literaria escolar, específicamente, el reconocimiento y la participación del lector literario, atendiendo a los modos en que la experiencia lectora es significada desde caminos explicativos divergentes sobre el conocimiento, para luego discutir las consecuencias didácticas de estas significaciones y su rol en el contexto de la justicia educativa como condición para la justicia social.

\section{2.- ¿Conocimiento literario? Primera aproximación al reconocimiento y la participación como problemas en la lectura literaria}

Para diversos autores (Colomer, 2OOI, 20I4; Cerrillo y Sánchez, 2OI7; Munita, 2OI7) la educación literaria es un constructo que representa un cambio de perspectiva en la enseñanza de la literatura. Con este enfoque, la preocupación se desplazó desde la transmisión historicista y patrimonial hasta situarse en el desarrollo de la competencia literaria.

Ya sea en la mirada patrimonial, historicista, competencial o experiencial, las inquietudes tanto por la enseñanza como por el aprendizaje de lo literario suponen concepciones particulares respecto del conocimiento, el conocedor y aquello que es susceptible de ser conocido. En este orden de cosas, la pregunta por el conocimiento de la literatura podría resolverse, siguiendo a Maturana (I995), a partir de dos caminos explicativos: el de la objetividad y el de la objetividad entre paréntesis.

En el primer camino, hegemónico en la constitución del pensamiento científico occidental y representado por el positivismo (von Glasersfeld, 20oo), se presupone la existencia de una realidad única que se constituye con independencia del observador y que lo precede, siendo, en consecuencia, aprehensible como algo que habita fuera de la experiencia del sujeto. En el segundo camino, aún emergente pero con importantes desarrollos teóricos en disciplinas tan heterogéneas como la cibernética (von Foester, 2005), la filosofía (von Glasersfeld, 2000, 2005; Morin, 1984, 1994), y la biología (Maturana, I988, ı990,I997; Varela, I996), la realidad se define como un fenómeno de la experiencia que emerge en el propio proceso de distinción del observador.

Siguiendo a Maturana (I997), en el camino explicativo de la objetividad entre paréntesis el conocimiento denota dos niveles distintos de experiencia. En primer lugar, el sujeto realiza una distinción en su experiencia del vivir (siempre determinada por su historia de interacciones) y, en tanto experiencia, esa distinción constituye conocimiento. En un segundo nivel, el observador elabora explicaciones sobre su distinción que funcionan como reelaboraciones de su experiencia y que se producen de un modo particular, de acuerdo con los criterios de legitimidad que existan en la comunidad de observadores a la que pertenece quien realiza la distinción.

En el plano del aprendizaje literario, concebir el conocimiento desde un camino explicativo u otro supone una especificación entre dos sentidos que informarán la acción didáctica: la literatura como una realidad existente por fuera del observador, por lo tanto, 
aprehensible y explicable, por una parte, y por otra, lo literario como una realidad que habita en la experiencia de quien participa en el encuentro, por lo tanto, experiencial en la propia transaccionalidad de lectura literaria. La idea anterior requiere tres apuntes: primero, respecto a lo literario, segundo respecto a su condición de explicabilidad y, tercero, respecto a lo transaccional.

En torno a lo literario existe evidencia teórica de su imposibilidad ontológica (Eagleton, 2009; Culler, 2OIO) pues no habría ninguna condición constitutiva de los textos o discursos que los hagan ser tales. En ese sentido, las comunidades de uso (a partir de repertorios de legitimidad) delimitan lo que es y lo que no es literario, operacionalizando reglas y modos de relación. De esto deviene la segunda precisión: su condición de explicabilidad.

Si lo literario es algo que habita fuera de la experiencia, su constitución consensual es aprehensible y explicable; si habita en la propia experiencia de literaturizar, es experimentable y creable en la transacción lectora. ¿Qué se enseña en la enseñanza de la lectura literaria? ¿Cuáles son los repertorios de uso y relación? Si se enseña la literatura como algo que habita fuera de experiencia, lo que se enseña es la serie de consensos establecidos como válidos, repertorios entre los que podríamos señalar: formas de leerla, relevancia legitimada de ciertas voces y, sobre todo, disposiciones específicas de comprensión de lectura.

En cuanto a lo transaccional, parece pertinente referir la propuesta de Rosenblatt (I996, 2002). Precisamente respecto a la dependencia o independencia del observador y la observación, su teoría de lectura transactiva supone una superación de la lectura como interacción. Mientras lo interactivo implica que tanto la obra como el lector aportan sus informaciones del mundo en el encuentro literario, lo transaccional advierte que las obras y los lectores se transforman, en la propia transacción, en una realidad única que existe solo en la experiencia del encuentro donde el conocedor, el conocimiento y lo conocido son parte de una unidad compleja en la que emergen múltiples significados.

Articulando las menciones realizadas, pudiéramos decir: la significación en el proceso de lectura literaria pudiera reconocer la existencia de una realidad explicable (contenida en los textos y contextos, por lo tanto, aprehensible en la comprensión lectora y la explicación) o ninguna existencia sino la propia transacción como realidad de significados posibles. La escolaridad, a propósito de la tecnificación homogeneizante, se inclina por reconocer los textos como fenómenos únicamente aprehensibles en la comprensión de lectura, en la presunción didáctica de una interacción entre lo que aporta el lector y lo que el mismo texto informa. La negación de algo explicable, por el contrario, supondrá que la propia experiencia de lectura literaria gatilla múltiples posibilidades de significación.

El reconocimiento de la condición de explicabilidad por sobre la condición de experiencialidad requiere otra revisión. Por cierto que, didácticamente, la explicación de los contextos de producción, recursos de lectura y disposiciones de análisis crítico permiten profundizar la literaturización escolar, sin embargo, pese a permitir acceder a 
las fronteras de las obras leídas, no faculta la emergencia de los propios significados, más aún, no legitima la creación posible nacida en la transacción.

La condición de experiencialidad, por el contrario, reconoce la propia experiencia significacional de la transacción como punto de partida a la experiencia literaria. Los múltiples significados (textuales, emocionales, biográficos, sociales, políticos, etc), al estar permanentemente ocurriendo son siempre expresables, sin embargo, requieren como condición inicial espacios legítimos de expresión; espacios que, marginados en la comprensión de lectura, se invisibilizan técnicamente como mecanismo inhabilitador de las condiciones experienciales de quien lee (Sánchez Lara, 20I9).

Conocimiento letrado, o conocimiento literario, desde la perspectiva desar rollada aquí, no es sinónimo entonces de comprensión en su sentido restringido, sino que refiere a conocimiento como quehacer, que está necesariamente determinado por la historia de experiencias previas de quien conoce, las cuales proveen el contexto desde el cual emergen los sentidos y significados encarnados en cada distinción que realiza el observador y que, al mismo tiempo, lo constituye como tal, en un proceso total no fragmentario (Maturana y Varela ,I994). Así las cosas, el observador que se constituye en el momento transaccional, está mediado por su historia de experiencias, por las múltiples posibilidades significacionales y por el conocimiento que se construye en la transacción ¿qué condiciones son reconocidas en la lectura literaria escolarizada?

En la lectura literaria significamos con nuestra historia de significados (Ibáñez, 2002), historia en la que no es posible disociar la emoción, la biografía, la serie de relaciones sociales, los relatos culturales y las disposiciones políticas. Al transformar la lectura literaria en un ejercicio exclusiva y excluyentemente de comprensión, descartando los múltiples significados posibles que se transan en el encuentro de intertextos lectores y vitales (Mendoza Fillola, 2OIO; Sanjuán, 2OI4), se parcializan tres reconocimientos didácticos: el del lector como agente que lee solo para comprender lo que habita fuera de su experiencia como realidad explicada; el de los textos como fenómenos aprehensibles en una dimensión técnica descartando la multiplicidad de la transacción; y la del docente que es relegado a la figura de un explicador de realidades independientes a quien observa.

Reconocer una parcialidad del lector implica que solo participa en el control de la comprensión y que su rol distribuido corresponde a la pasividad significacional. Su multiplicidad es invisibilizada. Reconocer la docencia como explicación de una realidad que ocurre fuera de experiencia, implica un marco metodológico acrítico que se diseña para el logro de estándares de lectura e instruccionalidad monomodal y monocultural. Su rol es desplazado a la frontera de la técnica explicativa. Los propios textos, en este reconocimiento, operan como objetos aprehensibles parcialmente para la reproducción cultural dentro del sistema didáctico literario.

Conviene retomar una precisión: al ser los reconocimientos afirmaciones de dimensiones sociales, políticas y epistémicas de los sujetos, conforme a marcos normativos y consensos culturales, resulta posible concluir según lo argumentado que, lo que opera en las comunidades escolares es un reconocimiento simplificado (inicialmente en la 
institucionalidad curricular y luego en las disposiciones didácticas) en que se afirma una dimensión excluyente de la lectura literaria: tecnología de control mediante condiciones de explicabilidad que remiten a una concepción epistémica de la literatura como una realidad que habita fuera de la experiencia.

Lo social se restringe al reconocimiento del lector como agente vacío de experiencias relacionales, lo político a cierta ilegitimidad participativa y lo epistémico a un espacio de inhabilitación de las capacidades generativas de significados. Dado además que los reconocimientos suponen habilitaciones a diversas formas participativas, siempre en relación con aquello legitimado como espacio de actuación, es posible colegir que las participaciones están informadas por la simplificación de la multiplicidad de dimensiones del sujeto.

2.I.- Experiencia y lectura literaria: Segunda aproximación al reconocimiento y la participación como problemas en la lectura literaria

Para Larrosa (2006) la experiencia es lo que nos pasa y no lo que ocurre. Toda experiencia de lectura está determinada, como acontecimiento, por algo ajeno que se constituye en propio en la misma experiencia acontecida y permite movilizarnos desde lo que se padece hacia lo que nos acontece. La lectura literaria nos ocurre, por ello es ocurrencia, en la transacción que se transforma en experiencia única y sobre la cual movilizamos nuestra multiplicidad.

Si bien la experiencia del conocer está siempre ocurriendo, la experiencia estética de la lectura literaria ocurre cuando el conocimiento experimentado adquiere cualidades nominales y expresiones legitimadas en la participación de la ocurrencia, pues, siguiendo a Dewey (2008), la experiencia es resultado transactivo que se reconoce en la participación y en la comunicación. Dicho de otra manera: la lectura literaria es una experiencia que pasa si solo es una explicación de la experiencia de otro que se aprehende en la comprensión de una dimensión formal, contextual o estructural (revelación de una realidad), por el contrario, es la experiencia que me pasa, si se transforma en espacio de expresión y conocimiento legitimado dentro de la ocurrencia transaccional (construcción de la realidad en la propia experiencia que ocurre).

$\mathrm{Si}$, como se ha dicho, los significados no están en quien lee ni en lo leído, sino en la emergencia de esa transacción, lo que pudiéramos decir tras lectura es una explicación de la experiencia transactiva o, lo que Maturana (1997) denomina una experiencia de segundo orden. Más aún: si en esta experiencia de lectura se reconoce la participación excluyente en respuestas de comprensión lectora, lo explicado como expresión de la experiencia opera también como un recorte de la multiplicidad de quien significa y, por tanto, ya no seríamos lo que somos en la transacción sino aquello que podemos ser en la dimensión simplificada de la comprensión como tecnología de control.

Reformulamos volviendo a los reconocimientos y la participación: si la propia experiencia lectora se reconoce, simplificadamente, como un acto de comprensión de lectura descartando la múltiple y compleja constitución de quien observa, tanto la 
experiencia transaccional como la experiencia expresada resultan fenómenos tecnificados de participación restringida, pues se expresan los significados como constataciones que dan cuenta de una aproximación siempre parcial a los universos de significados posibles.

La participación, dado el reconocimiento parcial de la experiencia, supone una tensión entre el conocimiento que se produce en la transacción, es decir en el propio acto de conocer conociendo la experiencia lectora, y el conocimiento que se espera producir. Si el significado que se construye se somete a evaluación teniendo como estándar los significados producidos por comunidades de observadores particulares (Maturana I997), entonces la lectura literaria escolar no solo debe ser repensada en los términos epistémicos del reconocimiento, sino que, además, en los términos políticos que operan en las circunstancias en que se legitiman los saberes que funcionan como universales en la medición de la experiencia.

Lave y Wenger (I99I) plantean la cuestión de la producción de conocimiento en el contexto de la práctica social (donde se ubica, por cierto, la lectura literaria) como un fenómeno situado. Esto significaría apartarse de la idea de que el proceso de aprendizaje es resultado de la internalización del conocimiento y desplazarse hacia la premisa de la construcción de saberes como resultado de la participación legítima en comunidades de práctica que delimitan el conocimiento que se experimenta y expresa. En este sentido, Maturana (1997) argumenta que tanto el conocimiento como el aprendizaje, son siempre comentarios del observador en función de su capacidad para englobar las acciones observadas, con el criterio de legitimidad que forma parte del ámbito explicativo compartido por la comunidad a la que pertenece. ¿Cómo opera esto en contexto del reconocimiento y la participación simplificadas en la escuela?

Si el reconocimiento didáctico refleja solo los sentidos y significados legitimados hegemónicamente, informados por la condición externa, parcial y técnica de la lectura literaria, los comentarios del observador estarán circunscritos a aquellos legitimados solo por la comunidad de práctica que reproduce estos valores hegemónicos, vale decir, comentarios reducidos al control de lo leído y sin posibilidad legítima de expresión. Si, por el contrario, el reconocimiento didáctico atiende la multiplicidad y complejidad de los sujetos, creando espacios para que sus sentidos y significados entren al aula, los criterios de legitimidad de la comunidad de observadores tendrían que ser construidos consensualmente a partir de la participación legítima de todos quienes forman parte de la interacción educativa.

Como cualquier otro tipo de conocimiento, el implicado en la lectura literaria referiría a los sentidos y significados que las personas producen en el flujo de su vivir, enmarcados en modos específicos de convivencia (Ibáñez, 20I5). De ahí que la condición política de la didáctica dialogue con el reconocimiento epistémico del conocedor y su experiencia, dado que los modos de convivencia literaria están delimitados por entramados complejos (intersecciones de repertorios canónicos del propio sistema literario con repertorios hegemónicos del sistema curricular), en los que interactúan discursos políticos de exclusión y disposiciones que inhabilitan tanto el reconocimiento 
complejo de la multiplicidad de los sujetos como la participación legítima a través de expresiones que excedan las validadas como tecnología de control.

2.2.- Reconocimiento y participación: sobre la necesidad de interpelar la educación literaria desde y para la justicia social

En este numeral, intentaremos poner las reflexiones anteriores en un contexto específico: lajusticia. Lajusticia social tieneimplicancias políticas, económicas, filosóficas y culturales en las que se entraman dimensiones distributivas, de reconocimiento y de participación (Antón, 2OI3; Murillo y Hernández, 2OII; Carneros, Murillo y MorenoMedina, 20I8). La dimensión distributiva refiere a la manera en que bienes, beneficios y sus mecanismos de acceso están distribuidos en las sociedades. Desde una perspectiva crítica, la distribución ha sido interpelada en cuanto a las condiciones y capacidades distribuidas, también por la dimensión económica de la distribución que no profundiza en las condiciones habilitantes, individuales, sociales y culturales del reconocimiento complejo.

$\mathrm{Al}$ respecto, Fraser $(2005,2008,2016)$ señala que las disposiciones de redistribución económica atañen a las injusticias de clase con base en desigualdades económicas, pero que, sin embargo, esas diferencias externas contienen distinciones culturales que no se transforman, pese a la coexistencia de principios, con la sola reorganización de bienes y recursos. Lo mismo acontece con el reconocimiento como política de identidad, donde no bastaría con reconocer las diversidades si no existe acciones que transformen las causas de sus marginaciones; unapolítica del reconocimiento requeriría, de este modo, reivindicaciones que excedan los discursos de identidad y los de distribución como cuestión de clase o de recursos.

Complementariamente, para Honneth (2006), el carácter retórico del reconocimiento consistiría en desplegar discursos que mantengan el sometimiento a un régimen de exclusión y generen conformidad ideológica, es decir, reconocimientos parciales y discursivos que reproducen las múltiples disposiciones de marginación. Un reconocimiento complejo, por el contrario, es, siguiendo al mismo autor, una afirmación moral que se ancla como ocurrencia acreditadora en lo cotidiano y lo social, por lo tanto, no deviene de discursos sin operatividad práctica ni subsiste en la negación de la legitimidad de quien participa del reconocimiento.

Esta distinción podría ser ampliada con dos observaciones: ocurrencia acreditadora y carácter retórico. La ocurrencia acreditadora (que antes se ha denominado participación legítima) exige la revisión de los marcos de valores y de las premisas culturales de convivencia. El reconocimiento que hemos llamado complejo presupone una reflexión en torno a las condiciones posibles de lo humano (experiencia, capacidad de construir significados y capacidad de distinguir la realidad en el propio conocer). Como se ha dicho, esta intersección constitutiva configura una multiplicidad inseparable; multiplicidad que, sin embargo, no es reconocida en todos los consensos sociales.

Cualquier atribución de cualidades que conformen el reconocimiento, al depender 
de los acuerdos culturales y sociales (Honneth, 2006), responde a las condiciones políticas e ideológicas donde operan dichos reconocimientos. En la lectura literaria, la participación lectora corresponde a lo políticamente declarado como acreditación en el marco de un reconocimiento parcial, lo que, generalmente, se traduce a derechos constitucionales de alfabetización, lecturas controlables, maneras restringidas de significación en disposiciones de comprensión lectora y conocimiento de obras y periodos consensuados como relevantes.

Legitimar la participación desde la multiplicidad de los sujetos y no desde los fines técnicos devenidos de una concepción de la realidad como categoría preexistente a la transacción, por el contrario, supondrá reconocer en acciones concretas la complejidad constitutiva. De esta premisa se desprende el apunte a lo retórico. Si solo la dimensión múltiple de los sujetos es reconocida en los discursos, por ejemplo curriculares, pero no representa acciones didácticas o evaluativas que reconozcan esa complejidad, el carácter retórico seguirá informando los grandes relatos educativos sin problematizar ni subvertir los mecanismos de exclusión.

Volvamos, dados los antecedentes, a las principales ideas del ensayo. El conocimiento literario tendría dos posturas epistémicas: la condición de explicabilidad de algo que ocurre fuera de la experiencia, o algo experimentable y expresable en la transacción lectora. Ambas posiciones informan distintos reconocimientos tanto de los lectores, las obras y los docentes, más aún, de las experiencias expresadas y las participaciones en la construcción de significados de quienes observan.

Participar legítimamente como múltiple es participar con la biografía, la emoción, la cultura y la expresión de los significados de manera legítima. El solo reconocimiento constitucional del derecho a leer, sin problematizar las condiciones epistémicas, políticas y didácticas, reconoce y habilita parcialmente la participación, más aún, las disposiciones y posiciones distribuidas para el funcionamiento simplificado de la lectura como tecnología de control.

En este sentido, el reconocimiento de determinadas literaturas y literacidades constituye una representación holográfica de la validación de las experiencias y, en consecuencia, de las realidades de quienes participan de ellas. Desde esta perspectiva y, retomando la propuesta de los estudios postcoloniales y subalternos (HernándezZamora 2OI9; Maldonado 2OI7; Quijano 2000), reorientar la educación literaria hacia la justicia social implicaría generar las condiciones para que en la escuela el subalterno pueda hablar (Spivak, 2003) y, más precisamente, para que pueda leer/leerse y escribir/ escribirse, tras el reconocimiento de las multiplicidades de la experiencia.

A partir de lo anterior y asumiendo que ha existido una evolución relevante en torno a la enseñanza de la literatura, más aún, que notables propuestas han permitido avanzar hacia la focalización del profesorado como sujeto lector didáctico (Munita, 2OI8), la condición emocional de la lectura literaria (Sanjuán, 2OI4), la escritura literaria como ejercicio de invención (Frugoni, 2006) y los proyectos de lectura y escritura como acciones de participación legítima (Margallo, 2OI2), consideramos que es relevante 
retornar a la experiencia humana como condición para la experiencia literaria y situarse en la discusión epistémica y política del reconocimiento del estudiantado.

Rosenblatt se pregunta: “'Acaso la sustancia de la literatura no es todo lo que los seres humanos han pensado, sentido o creado?" (2O02: 3I). Si es así, lo literario no debería sino reconocerse en el camino explicativo de la literatura como experiencia que habita en la transacción, es decir, y tal como se señala en el Diccionario de nuevas formas de lectura y escritura (20I3), como experiencia reflexiva que relaciona disposiciones emocionales, usos creativos e intertextos.

En esa premisa, los retos de la educación literaria no estarían solo en los mecanismos que permitan desarrollar la competencia literaria, sino, fundamentalmente, en reconocer la literatura como una manifestación social que exige en su didactización un relato político (Bombini, 2008) en el que se tenga como fin, al decir de Nussbaum (20I6), el desarrollo de capacidades que permitan deliberar respecto al bien común y los problemas de afectación cultural; que permitan empatizar, criticar y autocriticarse, y, sobre todo, desarrollar imaginación narrativa como metáfora en la que, la lectura literaria, supone una manera de comprenderse en el mundo y comprender otras realidades como multiplicidades afectadas por mecanismos de invisibilización.

\section{3.- Conclusiones}

Al comienzo se dijo que la institucionalización del fenómeno lector literario ha supuesto la adopción de ciertos modos relacionales y sentidos particulares definidos por discursos de poder, y que esos repertorios operacionalizan posiciones hegemónicas de tecnificación donde se instrumentalizan los procesos de aprendizaje y se simplifican las complejidades. En ese contexto, la premisa base que defendimos es que el problema de la lectura literaria escolar radica en la dimensión epistémica y política de los reconocimientos que en ella operan, además, que los reconocimientos parciales se traducen a participaciones ilegítimas y actualizaciones de injusticias que se reproducen en su didactización acrítica. Con el objetivo analizar el reconocimiento y la participación del lector literario escolar, se desarrollaron dos perspectivas: la experiencia lectora y la distinción de dos caminos explicativos del conocimiento. A partir de todo lo argumentado, podemos concluir que:

Las condiciones didácticas para la justicia social desde una justicia educativa, específicamente desde una justicia didáctica lectoliteraria, requieren avanzar desde la excluyente comprensión de universos contenidos en los textos, hacia la autocomprensión con posibilidades expresivas de los contenidos experienciales del mismo sujetocontinente. Planteado de otra forma: movilizar un compromiso político con la participación legítima del contenido de los sujetos en el reconocimiento complejo de sus riquezas experienciales.

Esta concepción de la lectura literaria escolar invita a exceder los límites de la 
reflexión metodológica respecto a cómo leer mejor, para situarse en lo político del por qué se lee, cómo lee y qué consensos deben ser repensados para reconocer la complejidad del lector literario, para establecer, en definitiva, nuevas condiciones participativas que legitimen las expresiones de sentido desde la multiplicidad.

El reconocimiento complejo del lector literario escolar supondrá reconocer, de esta manera, que lo literario no habita fuera de experiencia y que su condición de explicabilidad no preexiste a la de experiencialidad, así mismo, que la expresión de la experiencia como fenómeno de significación transaccional excede la constatación de la comprensión como técnica de control, y se ubica en la expresión legítima como participación posterior al reconocimiento de la historia de significados, de las posibilidades de construir conocimientos y de la facultad transactiva de ser lo que nos pasa por sobre lo que acontece.

Contrariamente, y en un contexto de múltiples tecnificaciones, la lectura literaria escolar operaría en reconocimientos parciales donde se reconoce la dimensión de control como exclusivo y excluyente consenso de experiencia, generando participaciones ilegítimas y transformando la preocupación política y epistémica en una serie de reducciones metodológicas orientadas al logro de competencias de lectura que reproducen la injusticia.

Notendría sentido en esta reflexión, sin embargo, negarque lalecturacomprensiva es parte de la complejidad de la lectura como ejercicio cultural. Pero la comprensión no está aislada de la emoción, menos de las posibilidades de expresión legítima, mucho menos de los marcos políticos de reconocimiento y participación. El riesgo de la tecnificación, a costo de lectores competentes, es reproducir las injusticias culturales y privar el derecho de agencia a través de la negación de la literatura como reunión de sujetos complejos y como encuentro de experiencias sensibles. 


\section{Referencias bibliográficas}

-Antón, A. (20I3). Igualdad y Libertad: Fundamentos de la Justicia Social, 2(I), Revista Internacional de Educación para la Justicia Social (RIEJS), 2 (I), I73-I94. Recuperado de http://www.rinace.net/riejs/numeros/vol2-numI/art9.pdf

- Bombini, G. (2008). La lectura como política educativa. Revista Iberoamericana de Educación, 46, I9-35. Recuperado de https://rieoei.org/historico/documentos/rie46aoI. pdf

- Carneros, S., Murillo, J. y Moreno-Medina, I. (20I8). Una aproximación conceptual a la Educación para la Justicia Social y Ambiental. Revista Internacional de Educación para la Justicia Social (RIEJS), 7(I), I7-36. Recuperado de https://doi.org/Io.I5366/ riejs20I8.7.I.OOI

- Caracas, B. y Ornelas, M. (20I9). La evaluación de la comprensión lectora en México. El caso de las pruebas EXCALE, PLANEA y PISA. Perfiles Educativos, 4I (I64), 8-27. Recuperado de http://www.scielo.org.mx/scielo.php?script=sci_arttext\&pid $=$ Sor85-269820I9O0O200008

- Cerrillo, P. y Sánchez, C. (20I7). Educación y competencia literarias (sobre la formación del lector literario). Revista Literatura em Debate, II(2I), 6-I9. Recuperado de http:// revistas.fw.uri.br/index.php/literaturaemdebate/article/view/2703/2282.

- Colomer, T. (200I). La enseñanza de la literatura como construcción de sentido. Lectura y vida. Revista latinoamericana de lectura, 22 (4), I-I9. Recuperado de http://www. lecturayvida.fahce.unlp.edu.ar/numeros/a22nI/22_oI_Colomer.pdf

- Colomer, T. (20I4). El aprendizaje de la competencia literaria. En c. Lomas. (Ed). La educación lingüística, entre el deseo y la realidad. Competencias comunicativas y enseñanza del lenguaje (pp.IIO-I22). Barcelona: Octaedro.

- Cuesta, C. (20I6). Lectura y escritura como contenidos de enseñanza de la lengua y la literatura: tensiones entre políticas educativas y trabajo docente en Argentina. En Sawaya, S. y Cuesta, C. (Coord). Lectura y escritura como prácticas culturales. La investigación y sus contribuciones para la formación docente (pp. 20-42). Mar del Plata: Universidad Nacional de la Plata.

- Culler, J. (20IO). Breve introducción a la teoría literaria. Barcelona: Crítica.

- Dewey, J. (2008). El arte como experiencia. Barcelona: Paidós.

- Eagleton, T. (2009). Una introducción a la teoría literaria. Ciudad de México: Fondo de Cultura Económica. 
- Ferreiro, E. (2004). Leer y escribir en un mundo cambiante. Conferencia expuesta en las Sesiones Plenarias del 26 Congreso de la Unión Internacional de Editores. Recuperado de https://dds.cepal.org/redesoc/publication?id= $=$ I886

- Fraser, N. (2005). Redefiniendo el concepto de justicia en un mundo globalizado. Anales de la Cátedra Francisco Suárez, 39, 69-87. Recuperado de http://revistaseug.ugr.es/index. $\mathrm{php} / \mathrm{acfs} /$ article/view/IO28

- Fraser, N. (2008). La justicia social en la era de la política de identidad: redistribución, reconocimiento y participación. Revista de Trabajo, 6 (4), 83-99. Recuperado de http:// trabajo.gob.ar/downloads/igualdad/o8ago-dic_fraser.pdf

- Fraser, N. (I febrero 20ı6). Igualdad, identidad y justicia social. Le Monde diplomatique en español. Recuperado de https://mondiplo.com/igualdad-identidad-y-justicia-social

- Frugoni, S. (2006). Imaginación y escritura: La enseñanza de la literatura en la escuela. Buenos Aires: Libros del Zorzal.

- Gamboa, A., Muñoz, P. A., y Vargas, L. (20I6). Literacidad: nuevas posibilidades socioculturales y pedagógicas para la escuela. Revista Latinoamericana de Estudios Educativos, I2 (I), 53-70. Recuperado de http://vip.ucaldas.edu.co/latinoamericana/ downloads/Latinoamericanar2(I)_4.pdf

- Gee, J. P. (20I5). The New Literacy Studies. The Routledge Handbook of Literacy Studies. Routledge. Web. 27 Aug 2018

- Heath, S.B. (2004) [1982]. El valor de la lectura de cuentos infantiles a la hora de dormir: habilidades narrativas en el hogar y en la escuela. En Zavala, V., Niño Murcia, M. y Ames, P. (Eds.). Escritura y sociedad. Nuevas perspectivas teóricas y etnográficas. Lima: Red para Desarrollo de las Ciencias Sociales en el Perú.

- Hernández-Zamora, G. (20r9). De los Nuevos Estudios de Literacidad a las Perspectivas Decoloniales en la investigación sobre literacidad. Íkala, Revista de Lenguaje y Cultura, 24(2), 363-86. Recuperado de http://www.scielo.org.co/pdf/ikala/v24n2/oI23-3432ikala-24-O2-OO363.pdf

- Honneth, A. (2006). El reconocimiento como ideología. Isegoría, o(35), I29-I5o. Recuperado de http://dx.doi.org/IO.3989/isegoria.20o6.i35·33

- Ibáñez, N. (2002). Las emociones en el aula. Estudios pedagógicos (Valdivia), (28), 3I-45. Recuperado de https://dx.doi.org/IO.4067/So7I8-O7O52002OOOIOOOO2

- Ibáñez, N. (20I5). La diversidad en la construcción de mundo de niños y niñas de dos culturas. Revista Latinoamericana de Ciencias Sociales, Niñez y Juventud, I3 (I), 357-368. Recuperado de http://www.scielo.org.co/pdf/rlcs/vi3ni/viзnıa22.pdf 
- Iribarren Donadeu, T. (20I6). Obras poéticas domésticas en Internet: Libertad y creatividad. ÁLabe, o(ı3). Recuperado de http://dx.doi.org/Io.I5645/Alabe2Or6.ı3.8

- Larrosa, J. (2006). Sobre la experiencia. Revista Aloma. Filosofía de l’educació, I9, 87-II2. Recuperado de http://dialnet.unirioja.es/servlet/articulo? $\operatorname{codigo}=22 \mathrm{OI} 3 \mathrm{I} 8$

- Lave, J. y Wegner, E. (т991). Situated Learning. Legitimate Peripheral Participation. Cambridge: Cambridge University press.

- Maldonado, B. (20I7). Geografía y territorialidad indígena: Innovación docente en la Escuela Normal Bilingüe e Intercultural de Oaxaca. Entreciencias: Diálogos en la Sociedad del Conocimiento, 5 (I4), I-22. Recuperado de http://dx.doi.org/Io.2I933/J.EDSC.2OI7. EI.O4

- Margallo, A. (2012). La educación literaria en los proyectos de trabajo. Revista Iberoamericana De Educación, 59, I39-I56. Recuperado de https://rieoei.org/RIE/article/ view/46o

- Martos Núñez, E. y Campos Fígares, M. (Eds.). (20I3). Diccionario de nuevas formas de lectura y escritura. Madrid: RIUL-Santillana.

- Maturana, H. (i988). Reality: The search for objetivity or the quest for acompelling argument. Irish Journal of Psychology, 9 (I), $25-82$.

- Maturana, H. (г99o). El sentido de lo humano. Santiago: Hachette.

- Maturana, H. (i995). La realidad: ¿Objetiva o Construida? Fundamentos biológicos de la realidad. Barcelona: Anthropos.

- Maturana, H. (i997). La objetividad. Un argumento para obligar. Santiago: Dolmen Ediciones.

- Maturana, H. (200I). Emociones y lenguaje en educación y política. España: Dolmen Ediciones.

- Maturana, H. y Varela, F. (I994). El árbol del conocimiento. Santiago: Paidós

- Mendoza Fillola, A. (20Iо). La competencia literaria entre las competencias. Lenguaje y Textos, 32, 2I-33. Recuperado de http://www.sedll.org/sites/default/files/journal/la_ competencia_literaria_entre_las_competencias._mendoza_a.pdf

- Morin, E. (1984). Ciencia con consciencia. Barcelona: Anthropos.

- Morin, E. (I994). Introducción al pensamiento complejo. Barcelona: Gedisa. 
- Munita, F. (20I7). La didáctica de la literatura: hacia la consolidación del campo. Educação e Pesquisa, 43(2), 379-392. Recuperado de https://dx.doi.org/Io.I590/si5I7970220I6I2I5I75I

- Munita, F. (20I8). El sujeto lector didáctico: “lectores que enseñan y profesores que leen”. Álabe, o(I7), I-I9. Recuperado de http://revistaalabe.com/index/alabe/article/view/408

- Murillo, F. y Hernández-Castilla, R. (2OII). Hacia un Concepto de Justicia Social. REICE. Revista Iberoamericana sobre Calidad, Eficacia y Cambio en Educación, 9(4), 8-23. Recuperado de https://revistas.uam.es/index.php/reice/article/view/432I

- Nussbaum, M. (20I6). Educación para el lucro, educación para la libertad. Nómadas, (44), I3-25. Recuperado dehttp://www.scielo.org.co/scielo.php?script=sci_arttext\&pid=SoI2I755 О2016ооогоооо $\& \operatorname{lng}=\mathrm{en} \& \operatorname{lng}=\mathrm{es}$.

- Ocampo, A. y López-Andrada, C. (20r9a). Acontecimientos de Lectura: experiencia política y compromiso ético. Alabe, o(2I). doi:http://dx.doi.org/Io.I5645/Alabe2O2O.2I.9

- Ocampo, A.y López-Andrada, C. (20I9b). Políticas culturalesy construcción de ciudadanía: ámbitos críticos para una justicia social. Polyphōnía. Revista de Educación Inclusiva, 3 (I), 78-Io3. Recuperado de https://revista.celei.cl/index.php/PREI/article/view/ı2O

- Quijano, A. (200o). Colonialidad del poder, eurocentrismo y América Latina. En E. Lander (Comp.), La colonialidad del saber: Eurocentrismo y ciencias sociales, perspectivas latinoamericanas (777-832). Buenos Aires: Clacso.

- Ramírez Leyva, E. (20IO). ¿Qué leer? ¿Qué es la lectura?. Investigación Bibliotecológica: archivonomía, bibliotecología e información, 23(47). Recuperado de http://dx.doi. org/IO.2220I/iibi.oI87358xp.2009.47.I696I

- Riquelme, A. y Quintero, J. (20I7). La literacidad, conceptualizaciones y perspectivas: hacia un estado del arte. Revista Reflexiones, 96 (2), 93-IO5. Recuperado de https://revistas. ucr.ac.cr/index.php/reflexiones/article/view/32084

- Rockwell, E. (20OI). La lectura como práctica cultural: conceptos para el estudio de los libros escolares. Educação e Pesquisa, 27 (I), II-26. Recuperado de http://www.redalyc. org/pdf/298/29827IO2.pdf.

- Rosenblatt, L. (I996). El modelo transaccional: la teoría transaccional de la lectura y la escritura. En L, Flower., J, Hayes, J. (Ed). Textos en contexto. Los procesos de lectura y escritura (pp.I-62). Buenos Aires: Lectura y vida.

- Rosenblatt, L. (2002). La literatura como exploración. Ciudad de México: Fondo de Cultura Económica. 
- Saavedra Rey, S. (2OII). La creación literaria en el ámbito educativo: De la estructura superficial a la construcción narrativa de la realidad. Lenguaje, 39(2), 395-4I7. Recuperado de http://www.scielo.org.co/scielo.php?script=sci_arttext\&pid=SoI2O$34792011000200005 \& \operatorname{lng}=\mathrm{en} \& \operatorname{lng}=\mathrm{es}$.

- Sánchez Lara, R. (20I9). Literatura, diversidad y educación: la urgencia de un observadorcreador desde la escritura autobiográfica. Polyphōnía. Revista de Educación Inclusiva, 3 (2), 236-254. Recuperado de https://revista.celei.cl/index.php/PREI/article/view/I43

- Sanjuán, M. (20I4). Leer para sentir. La dimensión emocional de la educación literaria. Impossibilia, 8, I55-I78. Recuperado de https://dialnet.unirioja.es/servlet/ articulo? codigo $=5372 \mathrm{I} 92$.

- Sawaya, S. (20i6). Las prácticas de lectura y escritura o el lugar del alumno como ciudadano. En Sawaya, S. y Cuesta, C. (Coord). Lectura y escritura como prácticas culturales. La investigación y sus contribuciones para la formación docente (pp. 9-19). Mar del plata: Universidad Nacional de la Plata.

- Spivak, G. (2003) ¿ ¿Puede hablar el subalterno? Revista Colombiana de Antropología, 39, 297-364. Recuperado de https://www.redalyc.org/pdf/IO5O/IO5OI8I8IoIo.pdf

-Varela, F. (1996). Ética y Acción. Santiago: Dolmen.

- von Foerster, H. (2003). Understanding. Essays on Cybernetics and Cognition. New York: Springer.

- von Glasersfeld, E. (2000). Despedida de la objetividad. En Watzlawick, P. y Krieg, P.(Comps). Elojo del observador (pp. 20-37). Barcelona: Gedisa.

- von Glasersfeld, E. (2005). Introducción al constructivismo radical. En Watzlawick, P. La realidad inventada (pp. 20-37). Barcelona: Gedisa.

- Zavala, V. (200I). Oralidad y escritura en la educación bilingüe. (A propósito de interculturalidad). Lima: GTZ y Ministerio de Educación

- Zavala, V. (2002). Desencuentros con la escritura. Escuela y comunidad en los Andes Peruanos. Lima: Red para el Desarrollo de las Ciencias Sociales en el Perú.

- Zavala, V. (2009). La literacidad o lo que la gente hace con la lectura y la escritura. En Cassany, Daniel (Ed.). Para ser letrados (pp.23-35). Barcelona: Paidos.

- Zavala, V. (2019). Justicia sociolingüística para los tiempos de hoy. Íkala, Revista de Lenguaje y Cultura, 24(2), 343-359. Recuperado de http://www.scielo.org.co/pdf/ikala/ v24n2/oI23-3432-ikala-24-O2-OO343.pdf 